\title{
Successful outcome of pregnancy in bicornuate uterus: a case report
}

\section{Suman Choudhary, Prasuna Jelly, Prakash Mahala*}

Department of Nursing, AIIMS Rishikesh, Uttarakhand, India

Received: 16 July 2019

Accepted: 13 September 2019

\section{*Correspondence:}

Mr. Prakash Mahala,

E-mail: prakashjpmmahala@gmail.com

Copyright: ( $)$ the author(s), publisher and licensee Medip Academy. This is an open-access article distributed under the terms of the Creative Commons Attribution Non-Commercial License, which permits unrestricted non-commercial use, distribution, and reproduction in any medium, provided the original work is properly cited.

\begin{abstract}
Bicornuate uterus is a major cause of spontaneous abortion. The recurrent pregnancy loss has been reported to the range of $15 \%$ to $27 \%$. There is different type of congenital uterine abnormalities like Bicornuate uterus, septate uterus, arcuate uterus, unicornuate uterus, didelphys uterus. It is important to consider this diagnosis in recurrent miscarriages, malpresentation, intra uterine growth restrictionand preterm deliveries. This report is about self at the age of 25-year-old pregnancy with a history of missed abortion. I was not diagnosing with a bicornuate uterus in my first pregnancy. However, I was diagnosed with a bicornuate uterus based on transvaginal ultrasound and hysterosalpingogram. A successful caesarean section was donein the $38^{\text {th }}$ week of gestation. According to the results, successful outcome could be achieved with bicornuate uterus. The outcome of bicornuate uterus was successful.
\end{abstract}

Keywords: Bicornuate uterus, Hysterosalpingogram, Outcome, Pregnancy, Self, Uterine malformation

\section{INTRODUCTION}

Congenital uterine deformities resulting from fusion of the mullerian ducts and abnormal formation. These abnormalities have been related with raised rate of failure miscarriage, premature delivery and aversive fetal consequence.

Reproductive capabilities of women can also affect by Bicornuate uterus. In the general population, uterine malformations are estimated $3 \%$ to $5 \% .^{2}$

Congenital malformation of uterus is one of the major cause of recurrent pregnancy loss and in patients it has been reported to range of $15 \%$ to $27 \% .^{3}$ Precise diagnostic test may be required to diagnose bicornuate uterus:

- Pelvic examination

- Hysterosalpingogram

- X-ray of the womb and fallopian tubes

- Transvaginal ultrasound

- Magnetic resonance imaging.
For a woman with repeated pregnancy losses, surgical intervention may be the only option available i.e. laparoscopic metroplasty, which results in a good unified uterine cavity and minimal adhesion formation. ${ }^{4}$ Therefore, a case of successful pregnancy outcome in a patient with bicornuate uterus is discussed in this report. The outcome can be improved through early diagnosis and close follow-up with proper treatment.

\section{CASE REPORT}

I was 25-year-old with previous history of missed abortion in the 7 week +2 days of gestation. No abnormal uterine abnormalities were reported by abdominal ultrasound in the first pregnancy. I attained menarche at the age of 14 year and menstrual history was not uneventful. I had no significant history of $\mathrm{Rh}$ incompability, diabetes mellitus, hypertension and any other type of rubella infection. No history of consanguineous marriage of parents. No family history of any abnormal pregnancies. After abortion of one year, I was anxious to conceive and came to GEM clinical 
nursing home Jaipur, Rajasthan. I was advised for routine investigation and transvaginal ultrasound. All blood tests were normal including thyroid profile, but transvaginal ultrasound report showed that (Table 1).

Table 1: Finding of transvaginal ultrasound report showing free fluid in uterus.

\begin{tabular}{|ll|}
\hline Bi-cornuate uterus & \multicolumn{1}{|l|}{ Findings } \\
\hline Uterus & $51 \mathrm{~mm}$ \\
\hline Transverse & $36 \mathrm{~mm}$ \\
\hline APD & $71 \mathrm{~mm}$ \\
\hline Long axis & \\
\hline $\begin{array}{l}\text { No mass or gestational sac } \\
\text { fluid was seen in uterus }\end{array}$ & $8 \mathrm{~mm}$ \\
\hline Endometrium (ET) & $30 * 24 \mathrm{~mm}$ \\
\hline RT ovary & $30 * 20 \mathrm{~mm}$ \\
\hline LT ovary & \\
\hline
\end{tabular}

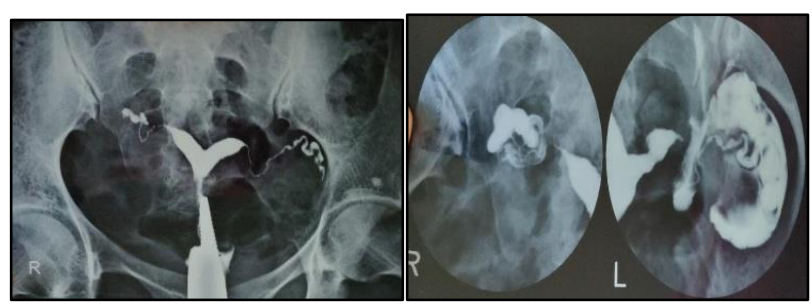

Figure 1: Hysterosalpingogram showing bicornuate uterus, patent left fallopian tube, partially blocked right fallopian tube with tubal adhesion.

So, the result was pelvic inflammatory disease, with bicornuate uterus and doctor prescribed capsule Doxy OD for 20 days. After completion of medical treatment, again doctor advised me about hysterosalpingogram. I underwent hysterosalpingogram and report showed that (Figure 1).

- Bicornuate uterus

- Patent left fallopian tube

- Partially blocked right fallopian tube with tubal adhesion.

I was advised by Doctor to undergo Metroplasty surgery (unification) with following medications.

\section{Cap. Estrafer XT 100 for 30 day}

2. Inj. Placentrax 15 for alternate day.

A study showed significant and persistent improvement of signs and symptoms of PID in women who received injection placentrax because it reduced the symptoms and signs of pelvic inflammatory disease such as abdominal pain, dysmenorrhoea and adnexal tenderness. ${ }^{5}$

Another study also shows that placentrax helps in specially to reduce the risk of tubal damage, infertility and formation of adnexal mass. ${ }^{6}$
It was also effective for me and finally, metroplasty surgery was done under spinal anaesthesia. Three months after metroplasty again hysterosalpingogram was repeated. The report showed that (Figure 2).

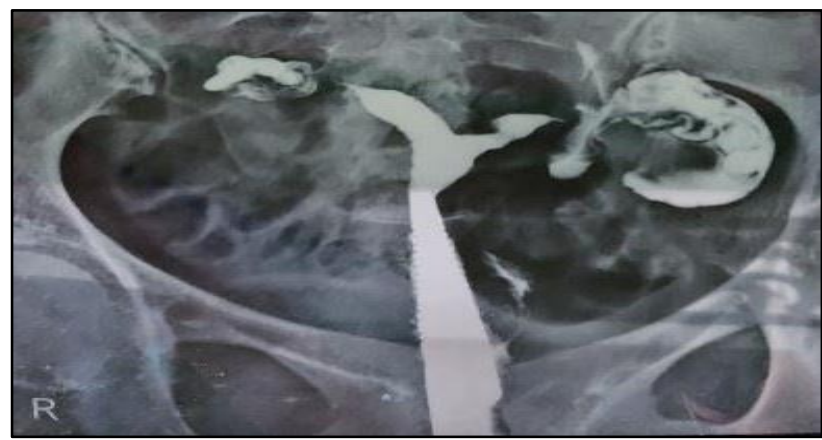

Figure 2: Hysterosalpingogram showing after metroplasty Bicornuate uterus with irregular left cornu, Bilateral patent fallopian tubes with right sided fimbrial adhesions.

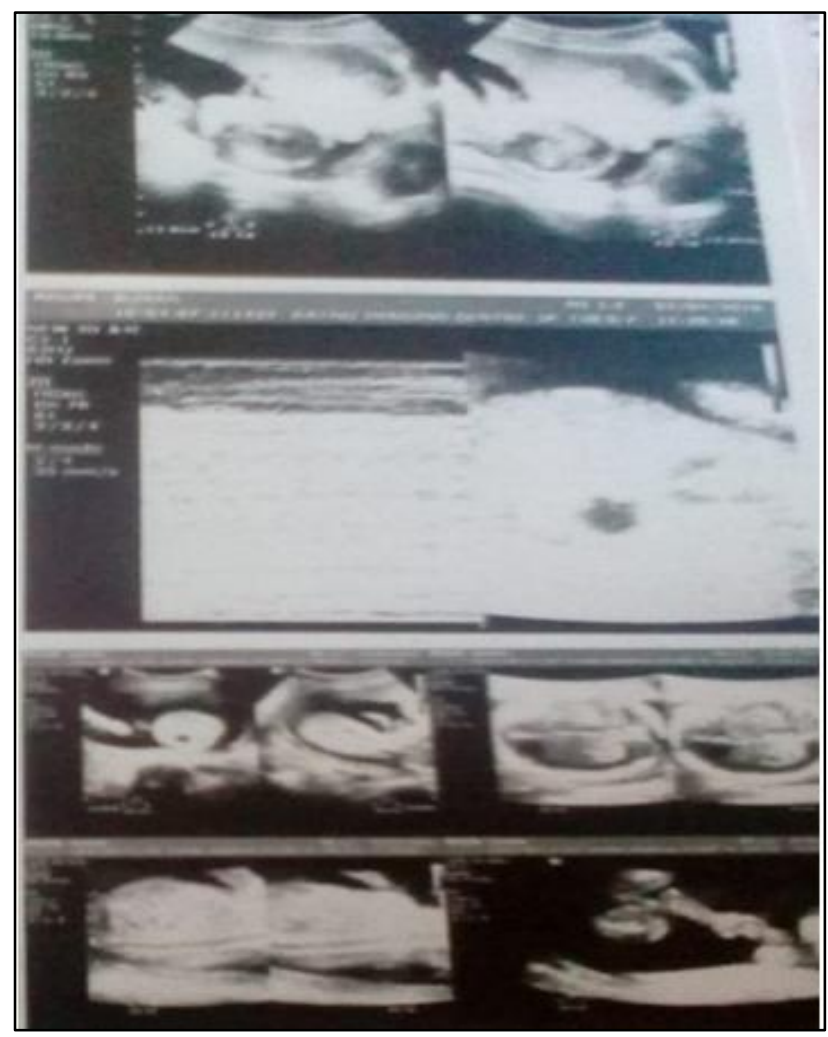

Figure 3: Abdominal ultrasound showing single viable foetus appox $16.2 \mathrm{wks}$ with anterior, low lying placenta.

After six months of metroplasty I conceived. The abdominal ultrasounds done in the 16 weeks +2 days of pregnancy confirmed the diagnosis and did not show any abnormality related to the foetus but placenta was anterior, low lying reaching the OS. So doctor advised me for review after 2-3weeks for placenta and anomalies (Figure 3). 


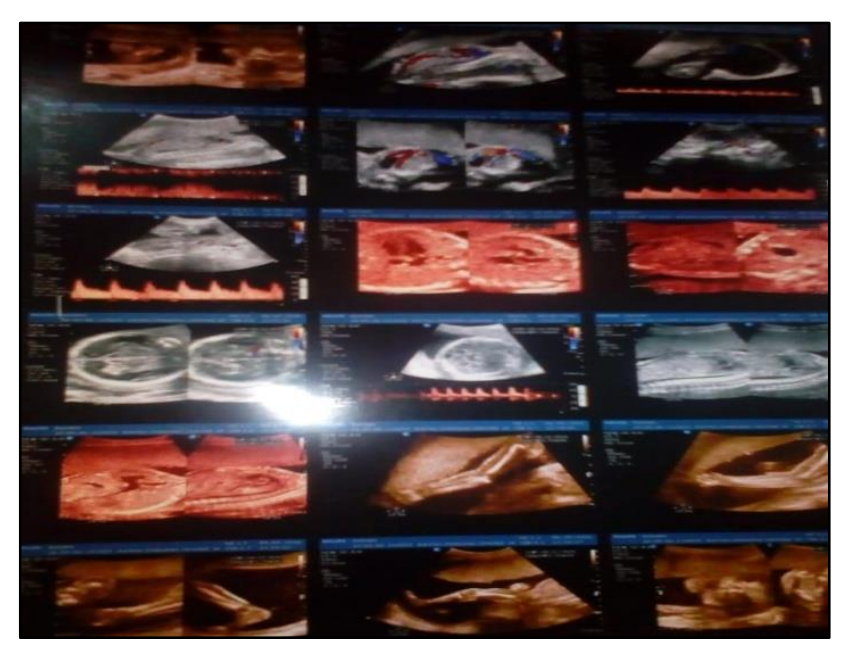

Figure 4: Single viable foetus approx. 20.6 weeks and placenta - anterior, body region well above the OS

The abdominal ultrasound was done again 20weeks 06day. In this report the placenta was in anterior upper segment (Figure 4).

But when foetus was growing, I felt too much back pain and discomfort then doctor advised me some complimentary therapies and effectives measure such as back massage. Change position, deep breath exercise etc. They were helpful in reducing pain and discomfort some study also showed that complimentary therapies and effective support measures are helpful in reducing pain and discomfort. ${ }^{7,8}$ I came in the 38 weeks of gestation to the GEM clinical nursing home without complaining of abdominal pain. I was not in labour and an ultrasound was repeated which showed breech Presentation of foetus with estimated weight of 3290 grams. No gross fetal anomalies were seen. Placenta was lying in the anterior wall. Amniotic fluid was also adequate. I was scheduled for elective caesarean section. A healthy male baby was delivered by lower segment caesarean section under spinal anaesthesia. The baby weight was 3300 grams with no congenital anomaly. Apgar score of 1 minute and 5 minute was 8 and 10 respectively and breast feeding initiated after 3hour of operation because it helps to reduces risk of babies having allergies and asthma and Breast milk comprises antibodies that help fight against bacteria and viruses. ${ }^{9}$ So The bonding of mother and baby is very important and breast feeding plays a vital role in providing immunity to neonate. ${ }^{10}$

\section{Psychological aspects}

I was so anxious to get conceive since one year after my first abortion. Then I came to know that I had bicornuate uterus with pelvic inflammatory disease, Patent left fallopian tube and partially blocked right fallopian tube with tubal adhesion and my anxiety was turned to double. Its impact was clearly visible on my personal and professional life and family member as well. Then I decided to go ahead with all coming issues regarding bicornuate uterus. Finally, my earlier anxiety turned with the grace of God and constant support of family members and team of health care personnel's.

\section{DISCUSSION}

Congenital uterine malformations are asymptomatic and relatively common. Women with uterine anomalies have lower pregnancy rates and lesser reproductive outcomes compared with women who have normal uterus. Early ultrasound is a contributing method for evaluation of the effects of abnormal uterus on pregnancy. ${ }^{11}$ In my case ultrasound could not identify the bicornuate uterus in my first pregnancy and hysterosalpingogram helped out me to diagnose to bicornuate uterus. After six month of unification I conceived and at the 38 weeks of gestation I was scheduled for caesarean section due to the breech position of the fetus. I delivered a healthy boy, weighing $3300 \mathrm{gm}$. I was stable after the caesarean section and discharged in overall healthy conditions after 5 day according to policy of hospital. So it was a successful outcome of bicornuate uterus. A bicornuate uterus does not always lead to complications and may carry a pregnancy to term. Women with bicornuate uterus might experience successful pregnancy. However, it seems essential to increase the patients' awareness towards the possible outcomes of bicornuate uterus by obstetricians. It is important to start a prenatal diagnosis to ensure proper care and prevent complications. ${ }^{2}$

\section{CONCLUSION}

Bicornuate uterus has an irregular shape of the uterus, which affect childbirth. It also increases the risk of miscarriage in the later stages of pregnancy, early delivery of baby due to irregular contraction of uterus or reduced uterus capacity also caused by unequal uterine shape. Bicornuate uterus is requiring extra monitoring because it is considering in high risk pregnancy. This condition always associated with increase rate of miscarriage. So antenatal check-up is essential in order to ensure appropriate management. It should be diagnosed before occurring of pregnancy. It will be beneficial for mother as well as baby also. If bicornuate uterus is diagnosed, to ensure proper care and prevent complications through the counselling of women about its prognosis, outcomes of pregnancy andmanagement (evidence based).

Funding: No funding sources Conflict of interest: None declared Ethical approval: Not required

\section{REFERENCES}

1. Chan YY, Jayaprakasan K, Zamora J, Thornton JG, Raine-Fenning N, Coomarasamy A. The prevalence of congenital uterine anomalies in unselected and high-risk populations: A systematic review. Hum Reprod Update. 2011;17(6):761-71. 
2. Borgohain D, Srivastava S. Case report pregnancy in bicornuate uterus. 2018;7(1):346-8.

3. Alborzi S, Dehbashi S, Parsanezhad ME. Differential diagnosis of septate and bicornuate uterus by sonohysterography eliminates the need for laparoscopy. Fertil Steril. 2002;78(1):176-8.

4. Alborzi S, Asadi N, Zolghadri J, Alborzi S, Alborzi M. Reply of the authors: Laproscopic metroplasty in bicornuate and didelphic uteri. Fertil Steril. 2009;92:4

5. Garg R, Zahra F, Chandra JA, Vatsal P. A comparative study of injection placentrex and conventional therapy in treatment of pelvic inflammatory disease. J Indian Med Assoc. 2008;106(7):18975504.

6. Agarwal N, Kulshrestha V, Kriplani A. Clinical eficacy of placentrex injection in pelvic inflammatory disease. $\mathrm{J}$ Indian Med Assoc. 2010;108(2):117-22.

7. Choudhary S, Prakash K, Mahalingam G, Mahala P. Effectiveness of labor support measures on the pain perception of mothers in labor. Int J Med Sci Public Heal. 2018;7(5):1.

8. Jelly P, Yadav R, Dey N. Complementary and alternative therapies in perinatal period. Curr Sce $\mathbf{J}$ Nurse Midwifery Mat Health. 2018;4(2):43.

9. Jelly P, Choudhary S. Breastfeeding and breast cancer: a risk reduction strategy. Int J Med Paediatr Oncol. 2019;5(2):47-50.

10. Mahala P, Choudhary S. Effects of tuberculosis in pregnancy. J Nurse Midwifery Maternal Health. 2019;5:2.

11. Souvizi B, Esfehani R. A case of successful pregnancy in a complete bicornuate uterus. J Midwifery Repro Health. 2016;4(3):720-2.

Cite this article as: Choudhary S, Jelly P, Mahala P. Successful outcome of pregnancy in bicornuate uterus: a case report. Int J Reprod Contracept Obstet Gynecol 2019;8:4086-9. 